ISBN 978-81-933894-1-6

International Conference on Studies in Disaster Management, Civil and Architectural Engineering

(SDMCAE-17)

Kyoto (Japan) April 18-19, 2017

\title{
Modelling of French High Speed Train Evacuation
}

\author{
Guillaume CRAVEUR ${ }^{1}$, Thierry DUPRE ${ }^{1}$, Camille SAUTOT $^{2}$, Jean-Charles CRAVEUR ${ }^{2}$ \\ ${ }^{1}$ SNCF, Rolling Stock Engineering Centre, 4 allée des Gémeaux 72100 Le Mans, France \\ ${ }^{2}$ ISMANS, 44 avenue F.A. Bartholdi, 72000 Le Mans, France
}

\begin{abstract}
Evacuation modelling technology offers designers and regulators of train new opportunities to rigorously test designs and theories in order to improve the passengers' safety. However, before evacuation models can be used effectively they need to be understood by the regulatory and train industry and validated. This paper tackles each of these aspects.

BuildingEXODUS models are used for this study. Firstly, in order to demonstrate the reliability of these tools to calculate the Required Safe Egress Time (RSET), a comparative study was realized between a real test and simulations with buildingEXODUS. Multiple simulations are performed to capture the stochastic variations in egress times. The philosophy of this comparative study is to realize the real test in one hand, and to use evacuation models with the incoming data (population, train geometry, initial position of the people) of the real test in an other hand. The goal is not to stall the simulations results with the real test but to see the results of calculations by themselves. Very good results were obtained and they permitted to put as evidence the fact that these tools can be used to calculate RSET for the rail industry.

Finally, this study shows advantages of evacuation modeling which allows realizing a lot of different simulations by changing the incoming data and which is less expensive than real scale test (it do not need the immobilization of a train and hundreds of volunteers). The results have important implications for rail safety because the application of evacuation modeling could supplant the real test imposed by the regulations. Moreover, with these tools, it is possible to compare train's architecture, to compare the evacuation time in function of the population, to simulate the evacuation with or without luggage, to simulate panic movement, to simulate fire propagation with the effects of smoke, heat...
\end{abstract}

Keywords: Transportation engineering, evacuation, high speed train

\section{Introduction}

The TGV $2 \mathrm{~N} 2$ is a high-speed train which consists of double-deck coaches. Passengers can move from a coach to the next via the upper deck. Passenger compartments of the lower deck have a single door providing access to the platform. The STI MR GV 2008, point 4.2.2.4.2.1.h, requires that all train passengers must be evacuated in less than 3 minutes. To validate this requirement, an egress experimental trial was performed in 2011. The evacuation of the two passenger compartments of coach R8 and the half upper compartment of coach R7 is representative of the complete trainset evacuation, and the trial concerned only these two coaches. The objective of the study is to model the egress experimental trial of coaches R7 and R8 with buildingEXODUS, and compare the computed results with the measured egress time.

\section{Modelling of the TGV 2 N2 evacuation with buildingEXODUS}

\subsection{Problem Definition}

Coach R8 consists of 92 seats, and the half upper passenger compartment of coach R7 consists of 26 seats. Thus the evacuation concerns 118 passengers who have to evacuate through the coach R8 door. 


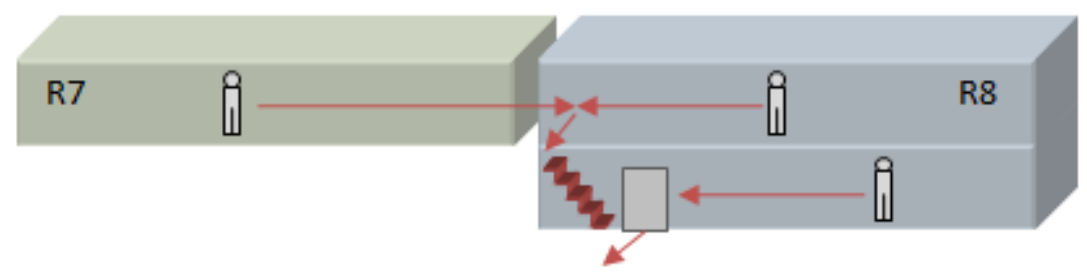

Fig 1: Coaches R7 and R8

Occupied seats are outlined in green on the Fig 2, and red arrows represent the way of evacuation.
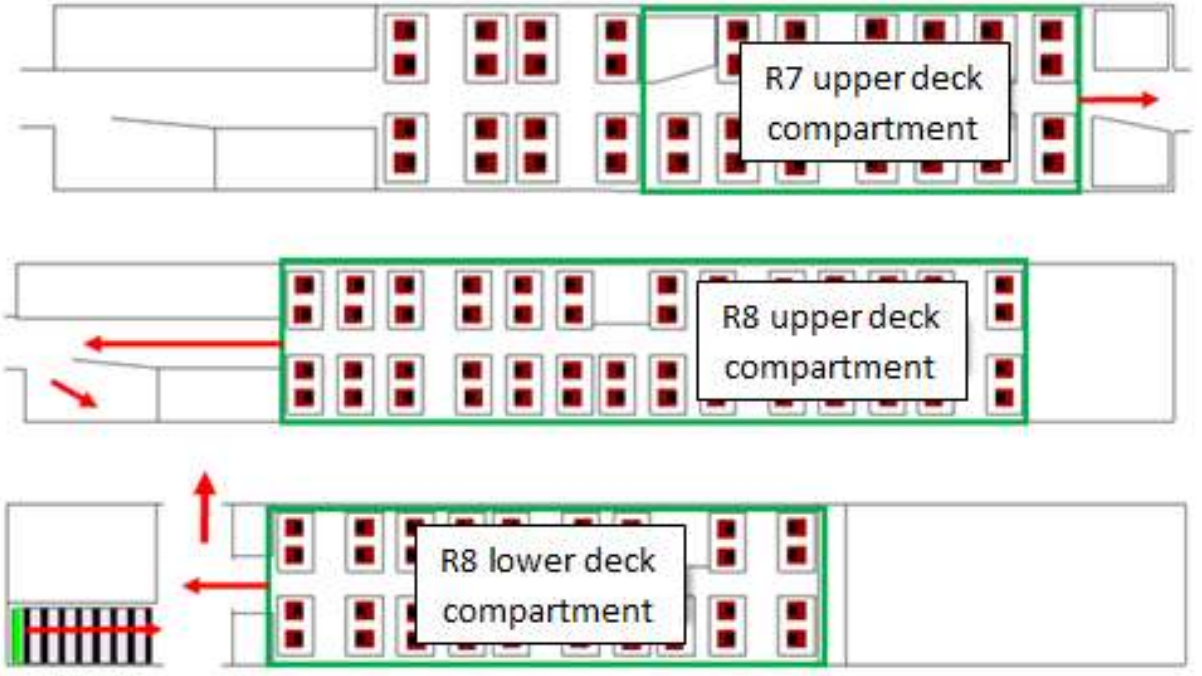

Fig 2: Occupied seats

During the experimental trial, passengers had a predefined seat and began to evacuate at the same as the timer started. All the passengers had to evacuate through the door of the coach R8. Timer stopped when the last passenger left the train. The measured egress time is equal to 126 seconds. [1]

The objective is to realize a model of the experimental test with several hypotheses about passenger displacements in the train. Results of the models will be compared to determine the influence of each hypothesis. And then computed results will be compared with measured egress time to evaluate the model accuracy.

\subsection{Modeling Realized}

There are 118 passengers whose 102 men and 16 women. Their seats are specified for the experimental trial, and this information is used for the data input.

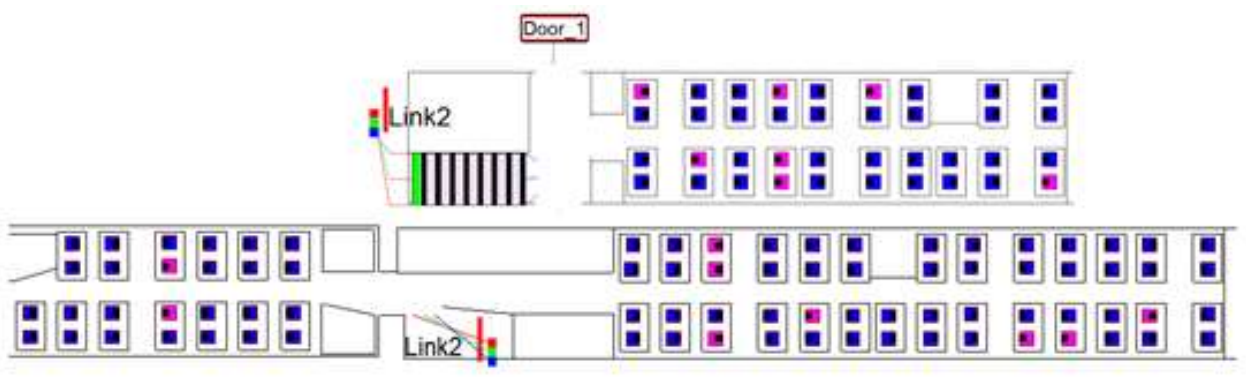

Fig 3: Passenger placement in coaches

During experimental trial, passengers begin to evacuate when the evacuation signal is given. Their response time is thus near to 0. In the buildingEXODUS model, the response time is assumed to be 0. Coach R8 stairs is assumed consisting in 1 lane. The same hypothesis is made for passenger compartment aisle because of it is 0.5 m wide. 
The influence of several parameters is studied with buildingEXODUS:

- Passengers evacuate through the right door or the left door,

- Passenger compartment doors are opened manually or with a push button,

- On the upper deck, out of passenger compartments, there are one or two lines of passengers,

- Two or three passengers can pretend to access to the stairs from the upper deck corridor,

- One or two passengers can go through the train door at the same time.

- Evacuation through right door or left door

The evacuation side is defined by the position of the train in relation to the platform. Evacuation could be performed by the left door (Door_1), or by the right door near to the stairs (Door_2).

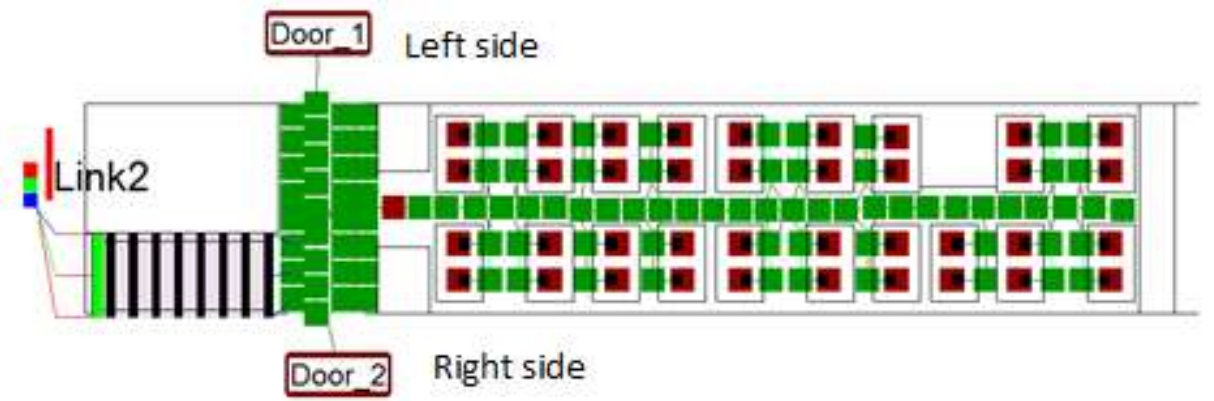

Fig 4: Right door and left door

Moreover, passenger compartment doors can be opened by three modes (opening times are defined below):

- Doors are constantly opened,

- Doors are manually opened,

- Doors are opened with a push button.

Number of passengers who could access to the stairs is defined by the access zone width. In view of the access zone geometry, it is assumed that two or three passengers can pretend to access to the stairs.

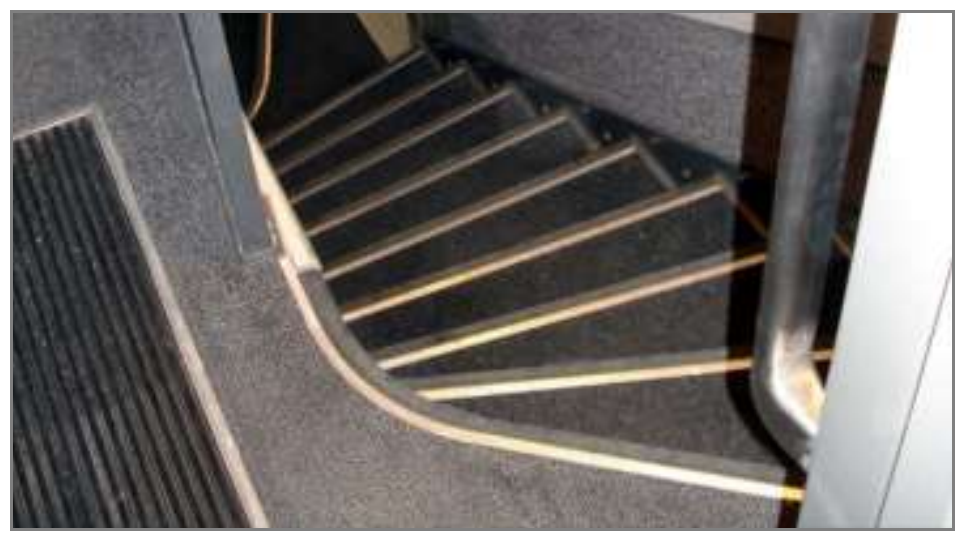

Fig 5: View of the stair access zone

It is assumed that one or two passengers can walk through the door at the same time. These two assumptions are traduced in buildingEXODUS by two meshes: one node is connected to the train door, or two nodes are connected. We consider thus that the exit has one or two lanes.

\section{Results}

\subsection{Passenger Evacuation Timeline}

Congestions in the train can be detected using population density contours in buildingEXODUS. 


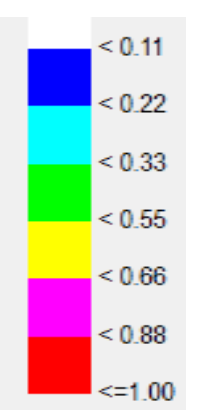

Fig 6: Population density (occupant $\left./ \mathrm{m}^{2}\right)$ in buildingEXODUS

During evacuation, congestions are observed in several places. Aisle congestions occur at the beginning of the evacuation, and are due to the compartment doors and to the wide aisle. Indeed, all the passengers have an instant response time and react at the same time.

Then, at 30 seconds, congestions are located at the top of the stairs and near to the exit.

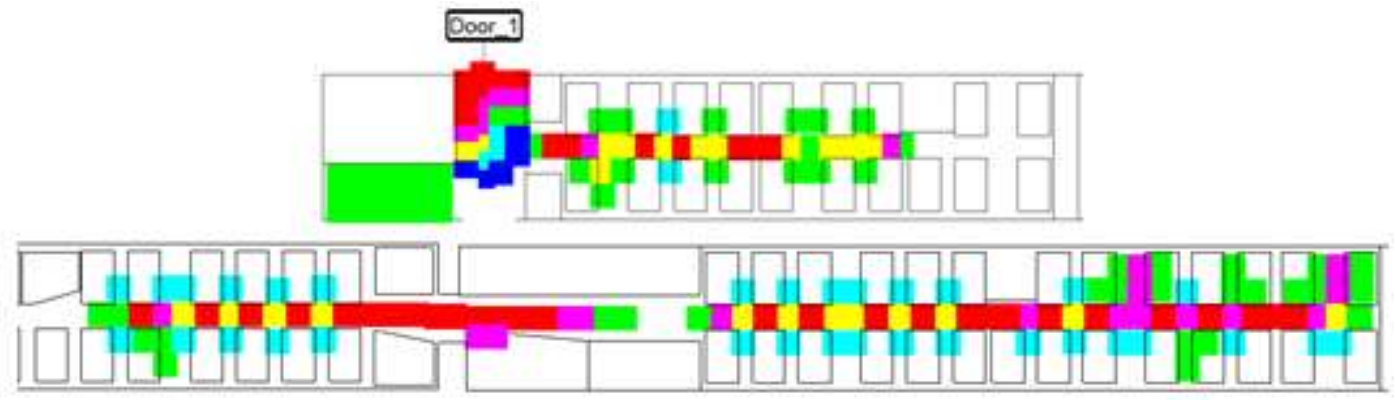

Fig 7: Population density at 30 seconds

At 75 seconds, compartment of the coach R8 lower deck has been evacuated. Evacuation of upper deck passengers is dimensioned by stair flow and exit flow.

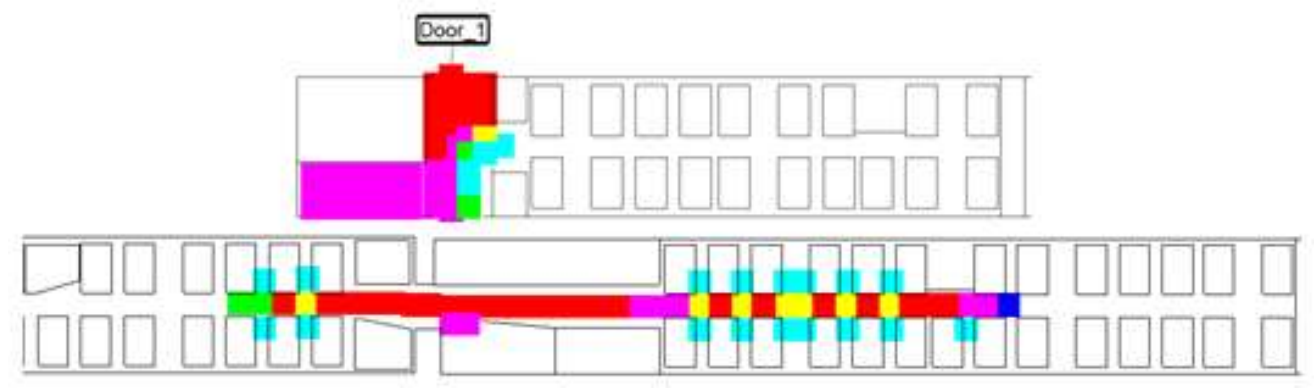

Fig 8: Population density at 75 seconds (mesh 1)

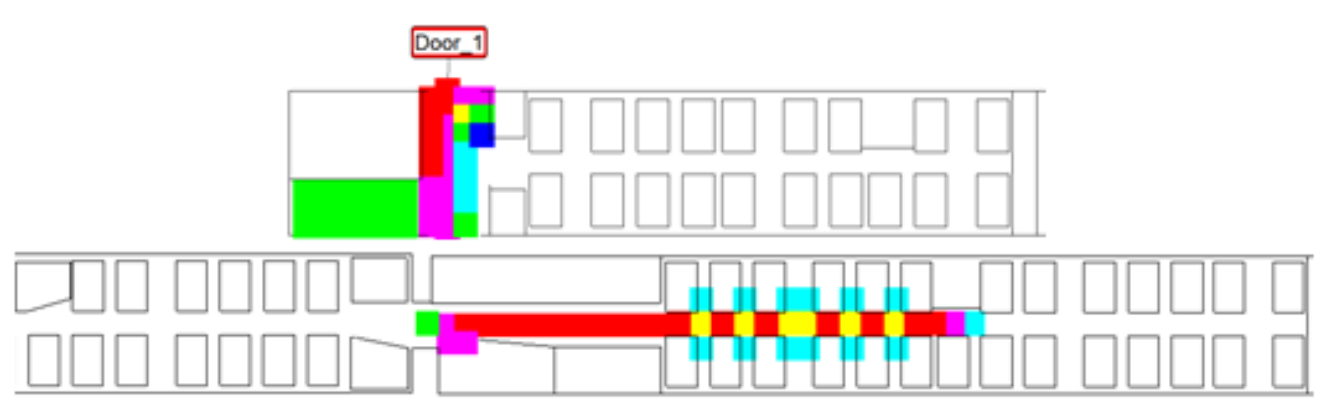

Fig 9: Population density at 100 seconds (mesh 1) 
At 100 seconds, coach R7 has been evacuated. Last passengers come from the compartment of the coach R8 upper deck. Only the flow exit is dimensioning the evacuation.

The same elements are observed for right and left side evacuation.

\subsection{Doors' Opening Influence}

We want to evaluate the influence of the compartment doors on the evacuation. These doors have three mode of opening: constantly opened, manually opened, or opened with a push button. In the second case, manual opening, doors are closed at the beginning of the simulation, and opened after 4 seconds. In the third case, opening with a push button, doors are opened after 3 seconds and for 180 seconds. Doors are then closed in 3 seconds and have to be opened again. The opening time of inter-coach doors is 2 seconds.

\begin{tabular}{|c|c|c|c|c|c|c|}
\cline { 2 - 7 } \multicolumn{1}{c|}{} & \multicolumn{6}{c|}{ Opening and closing times } \\
\cline { 2 - 7 } \multicolumn{1}{c|}{} & $\mathrm{O}$ & $\mathrm{C}$ & $\mathrm{O}$ & $\mathrm{C}$ & $\mathrm{O}$ & $\mathrm{C}$ \\
\hline Intercarriage door $(\mathbf{7 7 0} \mathrm{mm})$ & $2 \mathrm{~s}$ & $182 \mathrm{~s}$ & $186 \mathrm{~s}$ & $366 \mathrm{~s}$ & $370 \mathrm{~s}$ & $550 \mathrm{~s}$ \\
\hline Lower compartment door $(\mathbf{7 7 0} \mathbf{\mathrm { mm }})$ & $3 \mathrm{~s}$ & $183 \mathrm{~s}$ & $189 \mathrm{~s}$ & $369 \mathrm{~s}$ & $375 \mathrm{~s}$ & $555 \mathrm{~s}$ \\
\hline Upper compartment door $(700 \mathrm{~mm})$ & $3 \mathrm{~s}$ & $183 \mathrm{~s}$ & $189 \mathrm{~s}$ & $369 \mathrm{~s}$ & $375 \mathrm{~s}$ & $555 \mathrm{~s}$ \\
\hline
\end{tabular}

Fig 10: Opening times of compartment doors

Comparison is made with passengers evacuating by the left side exit.

Because of the randomness of many parameters, results are able to vary from a simulation to another [2]. That is why it is necessary to carry out several simulations for a model. For the evacuation of TGV 2N2, 100 simulations were carried out.

\begin{tabular}{|c|c|c|c|}
\hline Egress time (s) & $\begin{array}{c}\text { Push } \\
\text { button }\end{array}$ & $\begin{array}{c}\text { Manual } \\
\text { opening }\end{array}$ & $\begin{array}{c}\text { Opened } \\
\text { doors }\end{array}$ \\
\hline Maximum & 187 & 188 & 185 \\
\hline Minimum & 184 & 185 & 183 \\
\hline Average & 185 & 186 & 184 \\
\hline Variance & 1 & 1 & 1 \\
\hline S.D. & $1(0.5 \%)$ & $1(0.6 \%)$ & $1(0.5 \%)$ \\
\hline Error with trial (\%) & 47,0 & 47,9 & 45,9 \\
\hline
\end{tabular}

Fig 11: Egress time (s) in relation with opening mode of compartment doors

For these three cases, average egress time is between 184 and 186 seconds. The variance for these 100 simulations is equal to 1: results are not scattered and the average egress time is a faithful representation of the situation. Opening mode of the doors generates a variation of 2 seconds between the several computed egress times; it corresponds to a variation of $4 \%$ on the results. The manual opening induces the higher egress time: door opening takes 4 seconds and delays the evacuation. Nevertheless this value is negligible compared with the egress time.

\subsection{Mesh Influence}

Hypothesis about displacement of passengers in aisles and corridor are traduced by the different meshes realised. The four points following are compared:

- One or two lanes in the upper deck corridor

- Dimensions of the stair access zone

- Position of the stair access zone

- Exit consists in one or two lanes 
Comparisons are made for left side and right side evacuations. And for all the meshes, doors are opened with push buttons. Because of the randomness of many parameters, results are able to vary from a simulation to another [2]. That is why it is necessary to carry out several simulations for a model. For the evacuation of TGV $2 \mathrm{~N} 2,100$ simulations were carried out.

\begin{tabular}{|l|r|r|r|r|r|}
\cline { 2 - 7 } \multicolumn{1}{|c|}{ Left side evacuation } & \multicolumn{5}{|c|}{ Mesh } \\
\hline Egress time (s) & $\mathbf{1}$ & $\mathbf{2}$ & $\mathbf{3}$ & $\mathbf{4}$ & $\mathbf{5}$ \\
\hline Maximum & 187 & 187 & 187 & 187 & 131 \\
\hline Minimum & 184 & 184 & 184 & 184 & 120 \\
\hline \multicolumn{1}{|c|}{ Average } & 185 & 186 & 185 & 185 & 126 \\
\hline Variance & 1 & 1 & 1 & 1 & 12 \\
\hline S.D. & $1(0.5 \%)$ & $1(0.5 \%)$ & $1(0.4 \%)$ & $1(0.5 \%)$ & $3(2.7 \%)$ \\
\hline Error with trial (\%) & 47.0 & 47.3 & 46.7 & 47.0 & 0.2 \\
\hline
\end{tabular}

Fig 12: Egress time depending on the mesh (left side evacuation)

\begin{tabular}{|l|r|r|r|r|r|}
\cline { 2 - 7 } \multicolumn{1}{|c|}{ Right side evacuation } & \multicolumn{5}{|c|}{ Mesh } \\
\hline Egress time (s) & $\mathbf{1}$ & $\mathbf{2}$ & $\mathbf{3}$ & $\mathbf{4}$ & $\mathbf{5}$ \\
\hline Maximum & 186 & 187 & 187 & 190 & 130 \\
\hline Minimum & 184 & 184 & 184 & 184 & 120 \\
\hline Average & 185 & 185 & 185 & 186 & 125 \\
\hline Variance & 0 & 1 & 1 & 2 & 7 \\
\hline S.D. & $1(0.3 \%)$ & $1(0.6 \%)$ & $1(0.5 \%)$ & $1(0.7 \%)$ & $3(2.1 \%)$ \\
\hline Error with trial (\%) & 46.7 & 47.2 & 46.8 & 47.6 & 0.9 \\
\hline
\end{tabular}

Fig 13: Egress time depending on the mesh (right side evacuation)

The following observations are made in the both left side and right side evacuations.

For the meshes 1, 2, 3 and 4, egress time is between 184 and 190 seconds. Average egress time computed for these meshes is comprised 185 and 186 seconds, and the results have a variance less than 2. However the variation with experimental trial is near to $47 \%$. Thus the four models are not representative of the egress experimental trial realized. Moreover, the influence of studied parameters is negligible.

In the model 5, two passengers can walk through the exit at the same time. Exit flow has been multiplied by 2. This parameter has a significant impact on the average egress time. Indeed, an important exit flow reduces congestions and the average egress time is thus equal to 125 or 126 seconds. The variation with experimental trial is less than $1 \%$. This model is a great representation of the TGV $2 \mathrm{~N} 2$ evacuation.

\section{Conclusion}

Opening mode of the compartment doors, width of the stair access zone and number of lanes in upper deck corridor have no influence on the TGV 2N2 egress time. But congestions are located at the top of the stairs and before the exit. Thus these two points are dimensioning for the evacuation. Exit flow has an important impact on egress time. A double exit flow allows reducing congestions before the train door. With this hypothesis (two passengers can walk through the door at the same time) the average computed egress time is near to 125 or 126 seconds, and the variation with experimental results is less than $1 \%$. We can conclude that this hypothesis is a faithful representation of the real situation. 


\section{Acknowledgements}

I would like to thanks my colleagues at SNCF Rolling Stock Engineering Centre for the help they gave me to do this work. I also would like to thank Prof Ed Galea and senior research fellow Lazaros Filippidis from the Fire Safety Engineering Group of the University of Greenwich who taught me the human behavior and the practical use of buildingEXODUS for movement and evacuation. Finally I would like to thank Prof Jean-Charles Craveur from ISMANS Engineering School for his lectures and the Mastère Spécialisé in Fire Safety Engineering he developed at ISMANS engineering school.

\section{References}

[1] G. Craveur, "The use of evacuation modeling as a viable tool for the certification and safety analysis of passenger trains”, presented at the World Congress on Railway Research, Sydney, Australia, November 25-28, 2013

[2] G. Craveur, "Use of numerical evacuation tools to demonstrate the respect of lawful requirements for the rolling stock", in Proc. 6th International Conference on Applied Human Factors and Ergonomics and the Affiliated Conferences, 2015, Volume 3C, Pages 2365-2372

https://doi.org/10.1016/j.promfg.2015.07.384 